\title{
Race and Gender Differences in Obesity and Disease
}

\author{
Gloria Jones-Johnson', W. Roy Johnson'2, Natalia Frishman'1 \\ ${ }^{1}$ Department of Sociology lowa State University, Ames, lowa, USA \\ ${ }^{2}$ Department of Management lowa State University, Ames, lowa, USA \\ Email: gij@iastate.edu, wriohns@iastate.edu, natalia@iastate.edu
}

Received 30 April 2014; revised 3 June 2014; accepted 28 June 2014

Copyright (C) 2014 by authors and Scientific Research Publishing Inc.

This work is licensed under the Creative Commons Attribution International License (CC BY). http://creativecommons.org/licenses/by/4.0/

(c) (i) Open Access

\begin{abstract}
The objective of the present study was to examine race and gender differences in obesity and disease overtime. This topic is under studies in racial/ethnic minority populations. Yet, gender differences in health within ethnic groups provide a more nuanced approach to health disparities. The analyses for this study were based on two waves of data (Wave1, 1986 and Wave 2, 1989) of the Americans' Changing Lives Survey. The results revealed that a larger percentage of females are obese compared to males across all racial groups and females suffer a higher prevalence of disease compared to males which persists across time. The implications for cumulative disadvantage theory, feminist theory and the measurement of BMI and body fat are discussed.
\end{abstract}

\section{Keywords}

Obesity, Disease, Cumulative Disadvantage Theory, Feminism, BMI Gender and Race

\section{Introduction}

Several studies during the last few decades have illuminated the health risks of excess body weight (Kopelman, 2000; Ogden et al., 2006), but the prevalence of obesity in America has risen substantially during this time. Obesity is defined as a body mass index (BMI) that exceeds 30 (Schafer \& Ferraro, 2007). Obesity is a major public health problem in the US, particularly in racial/ethnic minority populations (Hedley et al., 2004; Ogden et al., 2006). The higher rate of obesity in minorities is often linked to the disproportionate representation of these groups in lower socioeconomic status (SES) categories (Gordon-Larsen, Dair, \& Popkin, 2003; Patterson et al., 1997; Zhang \& Wang, 2004). However, inadequate or improper specification of SES can bias estimates towards independent effects of race/ethnicity, which have the danger of being interpreted as "biological" effects of race (Kaufman, Cooper, \& McGee, 1997; Williams, 1997). Nevertheless, obesity prevalence is highest among 
Hispanics, African Americans and groups of low socioeconomic status (Wang \& Beydoun, 2007).

According to the Centers for Disease Control and prevention (CDC), the health risks associated with being "overweight" or "obese" include an increased risk of type 2 diabetes, heart disease, stroke, and hypertension (US Department of Health and Human Services, 2001). Type II diabetes is particularly prevalent among African Americans, partly due to genetics (Kumanyika, 1993; Sundquist \& Johnson, 1998) and lifestyle factors , such as obesity and inactivity (Calle et al., 2003; Kaplan, 2000; Must et al., 1999). Obese people are more likely than nonobese people to be female, black and less educated (Flegal et al., 1998).

\subsection{Gender and Obesity}

The prevalence of obesity continues to increase for women in the United States, particularly among African American and Mexican American women. According to Ogden et al. (2006) prevalence estimates from 1999 through 2004 based on data from NHANES indicate that African American women are at the greatest risk for developing obesity by midlife, with Mexican American women following. Ogden et al. (2006) estimated that 23.8\% of white women, 50.3\% of African American women, and 35.7\% of Mexican American women aged 20 39 years were obese. Moreover, the transition to adulthood is characterized by increasing obesity incidence and divergent racial/ethnic trends in obesity (Gordon-Larsen et al., 2004; Guo et al., 2000; Kimm et al., 2001).

The objective of the present study was to examine race and gender differences in obesity and disease over time. This topic is understudied in racial/ethnic minority populations including African American, Asian and Hispanic populations. Yet, gender differences in health within ethnic groups provide a more nuanced approach to health disparities research. Several studies found that men experience more life-threatening chronic diseases (e.g., heart disease) than women, whereas women have more nonfatal acute and chronic conditions (e.g., arthritis) than men (Bird \& Rieker, 2008; Courtenay, 2001; Williams, 2008). Moreover, Read and Gorman (2006) reported that black women are significantly more likely than their male counterparts to report life-threatening chronic diseases.

\subsection{Cumulative Disadvantage Theory}

According to Schafer and Ferraro (2007), overweight and obesity in early adulthood combines with the difficulty of sustained weight loss after becoming obese to portend a major demographic scenario of chronic obesity. The present research draws from cumulative-disadvantage theory to examine the interrelationship between race/ ethnicity, gender, obesity and disease. Knowing that a person's body mass index (BMI) exceeds 30 may be a useful piece of information in understanding the exposure to disease.

There is controversy as to whether cumulative disadvantage which began largely as a metaphor, is more of a perspective or model than a theory; however, it has been used as a theory by researchers to examine health outcomes (e.g. Ross \& Wu, 1996). Cumulative advantage has been variously referred to by scholars as cumulativeadvantage theory (Pampel \& Rogers, 2004), cumulative advantage/disadvantage theory (Dannefer, 2003), or the cumulative-adversity hypothesis (Hatch, 2005). Proponents of cumulative-disadvantage theory posit that advantages experienced early in life put one on a different pathway from those experiencing early disadvantage (Dannefer, 2003; Ferraro \& Kelley-Moore, 2003; O’Rand, 1996). According to Ross and Wu (1996), previous health research using cumulative-disadvantage theory views it largely as the growing gap between status groups in health outcomes with early disadvantage amplifying inequality over time. Emphasizing the development of health conditions over the life course implies that health status in later life is shaped by health status and resources earlier in the life course (Elder, 1994; Riley, 1987). We favor the view of cumulative disadvantage as a life course process, not just the difference in outcomes due to early disadvantage. For the present study, we view obesity as a health risk and assert that the duration of exposure to this risk is consequential to health over the life course.

\section{Hypotheses}

We examine the association between obesity and disease and propose three hypotheses. We hypothesize a positive relationship between disease and obesity. Second, we hypothesize that the relationship between disease and obesity would be stronger for women than men and for race/ethnic groups than whites. In addition, we expect the positive relationship between obesity and disease to persist overtime. 


\subsection{Methods}

\section{Participants}

The data come from the Americans' Changing Lives Survey, a stratified, multistage area probability sample of non-institutionalized adults age 25 and older living in the coterminous United States with over-sampling of both adults age 60 and older and African Americans. The wave 1 was conducted in 1986 and consisted of face-toface interviews with 3617 respondents (representing 70\% of sampled households and 68\% of sample individuals). Wave 2 conducted in 1989, also involved face-to-face interviews with 2867 (83\%) of wave 1 survivors. In 1994, approximately 7.5 years after baseline, wave 3 was conducted via telephone or face-to-face interviews with 2562 participants or their proxies (representing 83\% of wave 1 survivors). Additional information on the study design is published elsewhere (House et al., 1994; House et al., 1990). The analysis for this study was based on data from T1 (1986) and T2 (1989).

\subsection{Variables}

\subsubsection{Dependent Variables}

Disease at time 1 and time 2 are measures of prevalent health conditions. Prevalent disease is existing health conditions asked of the respondent such as during the last 12 months have you had heart attack, stroke, cancer, diabetes, high blood pressure, broken bones, foot problems, arthritis, lung disease and difficulty holding urine. Those who had the condition were given a score of 1 and all others a score of 0 . The conditions were then summed to create a prevalent disease measure ranging from 0 to 7 .

Persons with a body mass index greater than or equal to 30 are classified as obese and identified in a binary variable with a value of 1 and 0 .

\subsubsection{Independent Variables}

Socioeconomic status is measured with education, income, current employment and number of hours worked per week. Education is measured as total years of completed education. Total household income was measured as the combined income in the preceding year from all sources for respondents and their spouses in dollars. Current employment is a binary variable with those working having a value of 1 and all other 0 . Gender is coded (female $=1,0=$ male).

\subsubsection{Control Variables}

Several demographic variables are included in the models, such as age coded in years, race is five dummy variables that distinguish Whites $(\mathrm{N}=2339)$, African Americans $(\mathrm{N}=1174)$, Native Americans $(\mathrm{N}=138)$, Asians $(\mathrm{N}=33)$ and Hispanics $(\mathrm{N}=165)$.

The analysis was conducted in three stages. The first stage analyzed descriptive models of obesity by gender and race. The second stage estimated models of gender and disease and race and disease over time (T1 and T2). Finally, we estimated a model that predicts obesity at T1 (1986) and T2 (1989) with diseases and ocial and demographic control variables included.

\section{Results}

Table 1 presents obesity by gender. The results indicate that a larger percentage of females are obese compared to males across all racial groups including whites, African Americans, American Indians and Hispanics. However, the largest percent difference of thirteen points was between African American males and females, followed by American Indians with a nine point gender difference. Thus, African American and American Indian females are the most likely to be obese at T1. These results support hypothesis one.

Table 2 reveals that African Americans and American Indians have the highest and comparable rates of obesity (25\%). Hispanics have a higher percentage of obesity than whites. Thus, whites are less obese and African Americans and American Indians are most obese at both T1 and T2. These data support hypotheses one and two.

Table 3 reports gender and disease at T1 (1986) and T2 (1989). The results indicate that at T1 females have a higher percent of arthritis, hypertension, diabetes, foot problems and urine beyond control compared to males. The percentage results remain essentially the same at T2 (1989). Thus, females have a higher prevalence of disease compared to males which persist across time. These results support hypotheses two and three. 
Table 1. Obesity by Race and Gender. Obesity BMI $\geq 30$. T1 (1986).

\begin{tabular}{|c|c|}
\hline \multicolumn{2}{|c|}{ Whites } \\
\hline Males & Females \\
\hline $14 \%$ & $20 \%$ \\
\hline $193^{*}$ & 450 \\
\hline \multicolumn{2}{|c|}{$\underline{\text { Blacks }}$} \\
\hline $16 \%$ & $29 \%$ \\
\hline 64 & 228 \\
\hline \multicolumn{2}{|c|}{$\underline{\text { American Indians }}$} \\
\hline $19 \%$ & $28 \%$ \\
\hline 11 & 23 \\
\hline \multicolumn{2}{|c|}{$\underline{\text { Asians }}$} \\
\hline $0 \%$ & $1 \%$ \\
\hline 11 & 22 \\
\hline \multicolumn{2}{|c|}{$\underline{\text { Hispanics }}$} \\
\hline $18 \%$ & $22 \%$ \\
\hline 17 & 27 \\
\hline
\end{tabular}

Table 2. Obesity by Race. Obesity BMI $\geq 30$. T1 (1986).

\begin{tabular}{|c|c|c|c|c|}
\hline Whites & $\underline{\text { Blacks }}$ & American Indians & Asian Americans & $\underline{\text { Hispanics }}$ \\
\hline $14.5 \%$ & $24.8 \%$ & $24.6 \%$ & $.3 \%$ & $20.4 \%$ \\
\hline $340^{*}$ & 272 & 34 & 33 & 44 \\
\hline
\end{tabular}

"represents sample size.

The results for race and disease for T1 and T2 are presented in Table 4 and Table 5, respectively. Table 4 shows that at T1, whites, African Americans and American Indians have comparable rates of arthritis, hypertension, and foot problems. However, African Americans rate of hypertension was more than ten points higher than whites and American Indians. It is noteworthy that African Americans and American Indians have same percent of diabetes (14\%), however, there is a eight percent difference in the heart attack prevalence for American Indians compared to whites and African Americans with American Indians 18\% heart attack percent compared to whites $9 \%$ and blacks $10 \%$. American Indians also had a higher percent of broken bones compared to whites and African Americans. For Asians and Hispanics, the only diseases that were prevalent were arthritis, hypertension and foot problems. There was only a slight change in the percent for the diseases across the racial groups at T2 (1989), Table 5. These results provide support for hypothesis two.

Table 6 presents predictors of obesity at T1 and T2. Based on Equation (1), the educated are significantly less likely to be obese, whites are marginally significantly more likely to be obese and African Americans and American Indians are significantly more likely to be obese. As age increases, obesity increases; older people are more likely to be obese than younger people. Those who suffer with arthritis, hypertension or high blood pressure, and diabetes are more likely to be obese. About ten percent of the variance in obesity is explained by these variables. At T2, the predictors of obesity are virtually the same as T1 and nine percent of the variance in obesity is explained by the same variables. These results support hypothesis three. 
Table 3. Gender and Disease. Male $n=1358$. Female $n=2259$.

\begin{tabular}{ccccc}
\hline & \multicolumn{2}{c}{ T1 1986} & \multicolumn{2}{c}{ T2 1989} \\
\hline Disease & Males & Females & Males & Females \\
\hline 1. Arthritis & $31 \%$ & $45 \%$ & $30 \%$ & $45 \%$ \\
& $424^{*}$ & 1013 & 314 & 826 \\
2. Lung Disease & $5 \%$ & $4 \%$ & $6 \%$ & $5 \%$ \\
3. Hypertension & 62 & 99 & 60 & 100 \\
4. Heart Attack & $25 \%$ & $36 \%$ & $25 \%$ & $36 \%$ \\
& 346 & 817 & 259 & 630 \\
5. Diabetes & $8 \%$ & $9 \%$ & $8 \%$ & $10 \%$ \\
& 112 & 208 & 79 & 173 \\
6. Cancer & $8 \%$ & $10 \%$ & 85 & $11 \%$ \\
& 109 & 230 & $3 \%$ & 195 \\
7. Foot Problems & $2 \%$ & $3 \%$ & 31 & $3 \%$ \\
8. Stroke & 33 & 57 & $23 \%$ & 45 \\
& $23 \%$ & $36 \%$ & 238 & $32 \%$ \\
9. Broken bones & 311 & 804 & $2 \%$ & 582 \\
& $1 \%$ & $1 \%$ & 24 & $2 \%$ \\
10. Urine beyond control & 12 & 19 & $4 \%$ & 30 \\
& $5 \%$ & $6 \%$ & 45 & $5 \%$ \\
\hline
\end{tabular}

${ }^{*}$ represents sample size.

\section{Table 4. Race and disease.}

\begin{tabular}{cccccc}
\hline \multirow{2}{*}{ Disease } & Whites & Blacks & American Indians & Asians & Hispanics \\
\hline 1. Arthritis & $40 \%$ & $42 \%$ & $49 \%$ & $21 \%$ & $14 \%$ \\
2. Lung Disease & 909 & 490 & 67 & 7 & 3 \\
3. Hypertension & $5 \%$ & $3 \%$ & $9 \%$ & $0 \%$ & $3 \%$ \\
4. Heart Attack & 125 & 33 & 12 & - & 1 \\
5. Diabetes & $27 \%$ & $43 \%$ & $30 \%$ & $18 \%$ & $24 \%$ \\
6. Cancer & 635 & 505 & 42 & 6 & 6 \\
& $9 \%$ & $10 \%$ & $18 \%$ & $9 \%$ & $8 \%$ \\
7. Foot Problems & 199 & 115 & 25 & 3 & 2 \\
& 169 & $14 \%$ & $14 \%$ & $3 \%$ & $3 \%$ \\
8. Stroke & $3 \%$ & 161 & 19 & - & 1 \\
& 68 & $18 \%$ & $4 \%$ & - & - \\
9. Broken bones & $69 \%$ & $36 \%$ & $64 \%$ & $24 \%$ & $18 \%$ \\
10. Urine beyond control & $6 \%$ & 424 & 47 & 8 & 4 \\
& $1 \%$ & $1 \%$ & $1 \%$ & - & $3 \%$ \\
\hline
\end{tabular}

Whites $n=2339$; Blacks $n=1174$; American Indian $n=138$; Asian $n=33$; Hispanic $n=43$. 
G. Jones-Johnson et al.

Table 5. Race and disease.

\begin{tabular}{|c|c|c|c|c|c|}
\hline \multirow[b]{2}{*}{ Disease } & \multicolumn{5}{|c|}{ T2 1989} \\
\hline & Whites & $\underline{\text { Blacks }}$ & $\underline{\text { American Indians }}$ & $\underline{\text { Asians }}$ & Hispanics \\
\hline \multirow[t]{2}{*}{ 1. Arthritis } & $39 \%$ & $44 \%$ & $48 \%$ & $22 \%$ & $15 \%$ \\
\hline & 737 & 383 & 57 & 5 & 4 \\
\hline \multirow[t]{2}{*}{ 2. Lung Disease } & $7 \%$ & $3 \%$ & $10 \%$ & $4 \%$ & $4 \%$ \\
\hline & 124 & 30 & 12 & 1 & 1 \\
\hline \multirow[t]{2}{*}{ 3. Hypertension } & $27 \%$ & $42 \%$ & $33 \%$ & $13 \%$ & $23 \%$ \\
\hline & 511 & 366 & 39 & 3 & 6 \\
\hline \multirow[t]{2}{*}{ 4. Heart Attack } & $9 \%$ & $9 \%$ & $14 \%$ & - & $8 \%$ \\
\hline & 169 & 78 & 17 & - & 2 \\
\hline \multirow[t]{2}{*}{ 5. Diabetes } & $8 \%$ & $15 \%$ & $16 \%$ & - & $4 \%$ \\
\hline & 145 & 130 & 19 & - & 1 \\
\hline \multirow[t]{2}{*}{ 6. Cancer } & $3 \%$ & $1 \%$ & $6 \%$ & - & - \\
\hline & 64 & 10 & 7 & - & - \\
\hline \multirow[t]{2}{*}{ 7. Foot Problems } & $27 \%$ & $32 \%$ & $34 \%$ & $30 \%$ & $19 \%$ \\
\hline & 517 & 281 & 40 & 7 & 5 \\
\hline \multirow[t]{2}{*}{ 8. Stroke } & $2 \%$ & $3 \%$ & $3 \%$ & - & $4 \%$ \\
\hline & 28 & 26 & 4 & - & 1 \\
\hline \multirow[t]{2}{*}{ 9. Broken bones } & $5 \%$ & $4 \%$ & $10 \%$ & - & $4 \%$ \\
\hline & 98 & 37 & 12 & - & 1 \\
\hline \multirow[t]{2}{*}{ 10. Urine beyond control } & $7 \%$ & $7 \%$ & $13 \%$ & $4 \%$ & $4 \%$ \\
\hline & 133 & 62 & 15 & 1 & 1 \\
\hline
\end{tabular}

Table 6. Predictors of obesity T1 (1986) and T2 (1989).

\begin{tabular}{|c|c|c|c|c|}
\hline & \multicolumn{2}{|c|}{ Obesity T1 } & \multicolumn{2}{|c|}{ Obesity T2 } \\
\hline & \multicolumn{2}{|c|}{ Equation (1) } & \multicolumn{2}{|c|}{ Equation (2) } \\
\hline Variable & $\underline{\text { Coeff }}$ & $\underline{\text { Std Error }}$ & $\underline{\text { Coeff }}$ & $\underline{\text { Std Error }}$ \\
\hline Constant & $1.20^{* *}$ & 0.17 & $1.08^{* *}$ & 0.14 \\
\hline Education & $-0.04^{* *}$ & 0.01 & $-0.03^{* *}$ & 0.01 \\
\hline Gender & -0.02 & 0.02 & -0.02 & 0.02 \\
\hline White & $0.02_{0.06}$ & 0.01 & 0.01 & 0.01 \\
\hline Black & $0.04^{* *}$ & 0.01 & 0.01 & 0.01 \\
\hline American Indian & $0.02^{*}$ & 0.01 & 0.08 & 0.07 \\
\hline Hispanic & 0.04 & 0.07 & $0.03^{* *}$ & 0.01 \\
\hline Age & $0.03^{* *}$ & 0.01 & 0.01 & 0.01 \\
\hline Income & 0.01 & 0.01 & $0.01^{* *}$ & 0.01 \\
\hline Arthritis & $0.02^{* *}$ & 0.01 & $0.02^{*}$ & 0.01 \\
\hline Lung disease & $0.02_{0.06}$ & 0.01 & $0.03^{*}$ & 0.01 \\
\hline Hypertension & $0.04^{* *}$ & 0.01 & $0.03^{*}$ & 0.01 \\
\hline Heart attack & 0.01 & -0.01 & 0.01 & 0.01 \\
\hline Diabetes & $0.02^{* *}$ & 0.01 & $0.03^{* *}$ & 0.01 \\
\hline Cancer & -0.01 & 0.01 & 0.01 & 0.01 \\
\hline Foot problems & 0.01 & 0.01 & 0.01 & 0.01 \\
\hline Stroke & 0.01 & 0.02 & -0.02 & 0.01 \\
\hline Broken bones & -0.03 & 0.01 & -0.01 & 0.01 \\
\hline \multirow[t]{3}{*}{ Urine beyond control } & 0.01 & 0.01 & $0.02^{*}$ & 0.01 \\
\hline & \multicolumn{2}{|c|}{$F=15.88$} & \multicolumn{2}{|c|}{$F=14.27$} \\
\hline & \multicolumn{2}{|c|}{$\mathrm{R}^{2}=0.10$} & \multicolumn{2}{|c|}{$\mathrm{R}^{2}=0.09$} \\
\hline
\end{tabular}




\section{Discussion}

Drawing upon cumulative-disadvantage theory, we investigated race and gender differences in obesity and disease over time. The results of the study support our hypotheses and prior research that shows excessive body mass leads to disadvantages that accumulate over time (Ferraro \& Kelley-Moore, 2003). The present analyses revealed race and gender differences in obesity and disease over time. For example, women experienced more nonfatal acute chronic conditions such as arthritis, foot and urine problems compared to males which is similar to prior studies (Bird \& Rieker, 2008; Courtenay, 2001; Williams, 2008). Consistent with prior research (Ogden et al., 2006), there were higher rates of obesity among females, especially among African American and Mexican females. The higher obesity rates among African Americans and Indians suggest that exploring racial/ethnic differences in relationships between SES and health can provide insight on racial/ethnic disparities (Farmer \& Ferraro, 2005; Shuey \& Wilson, 2008).

The race and gender differences in obesity and disease indicate that measurement of overweight and obesity need to be race and gender specific. According to Prentice and Jebb (2001), there is increasing awareness that certain ethnic groups, such as Asians and African Americans, display a very different relationship between BMI and body fat to that described for Caucasians. Thus, these ethnic groups may be unfairly classified as overweight and obese by a system based primarily on Caucasian standards. Moreover, the BMI cutoff adopted by the World Health Organization (WHO) has the same cut-off values for men and women (Prentice \& Jebb, 2001). Future studies of the measurement of excess body fat need to consider qualitative studies that include culture, beliefs and attitudes of the populations that are measured.

Consistent with prior research, our results show that obesity heightens the risk of multiple comorbid conditions, especially diabetes, heart disease, and hypertension (Kopelman, 2000). In addition, our results support prior research findings that obese people are more likely than non obese people to be female, black and less educated (Flegal et al., 1998). The significant effect of age on obesity support Ferraro and Kelley-Moore (2003) contention that the consequences of obesity for health vary according to the timing of onset, with early obesity escalating risk. According to Prentice and Jebb (2001), the relationship between BMI and body fat is age-dependent and the discrepancies are accentuated after middle age and during the menopause in women.

We believe this study offers promising directions for tenets of cumulative-disadvantage theory which suggest that, over time, heterogeneity increases between different groups based upon their relative advantage or disadvantage (Ross \& Wu, 1996). Although there were race and gender differences in obesity, race but not gender was a significant predictor of obesity. This finding indicate that race and gender analysis of obesity provide a nuance approach to cumulative disadvantage. In addition, a feminist analysis of the life course perspective of cumulative disadvantage would provide greater specificity of divergent trajectories of obesity and disease by gender. It is time that obesity specialists advocate for establishing the average level of body fat equivalent to the BMI criteria already established in order to increase our understanding of the developing epidemic of obesity and its attendant health risks by race/ethnicity and gender. Obesity is highly related to major types of diseases and contributes to increased health care costs. The prevention and treatment of obesity are critical to decrease the 21st century epidemics of obesity and diabetes. There is a growing debate that obesity is a type of disease that has implications for health equity and access to affordable health care in the US and the world.

\section{Acknowledgements}

The authors thank the reviewers for their helpful comments.

\section{References}

Bird, C., \& Rieker, P. (2008). Gender and Health: The Effects of Constrained Choices and Social Policies. New York : Cambridge University Press. http://dx.doi.org/10.1017/CBO9780511807305

Calle, E. E., Rodriguez, C, Walker-Thurmond, K., \& Thun, M. J. (2003). Overweight ,Obesity, and Mortality from Cancer in a Prospectively Studied Cohort of U.S. Adults. New England Journal of Medicine, 348, 1625-1638. http://dx.doi.org/10.1056/NEJMoa021423

Courtenay, W. H. (2001). Constructions of Masculinity and Their Influence on Men’s Well-Being: A Theory of Gender and Health. Social Science \& Medicine, 50, 1385-1401. http://dx.doi.org/10.1016/S0277-9536(99)00390-1

Dannefer, D. (2003). Cumulative Advantage/Disadvantage and the Life Course: Cross-Fertilizing Age and the Social Science Theory. Journal of Geontology: Social Sciences, 58B, S327-S337. http://dx.doi.org/10.1093/geronb/58.6.S327 
Elder, G. H. (1994). Time, Human Agency, and Social Change: Perspectives on the Life Course. Social Psychology Quarterly, 57, 4-15. http://dx.doi.org/10.2307/2786971

Farmer, M. M., \& Ferraro, K. F. (2005). Are Racial Disparities in Health Conditional on Socioeconomic Status? Social Science \& Medicine, 60, 191-204. http://dx.doi.org/10.1016/j.socscimed.2004.04.026

Ferraro, K. F., \& Kelley-Moore, J. (2003). Cumulative Disadvantage and Health: Long Term Consequences of Obesity? American Sociological Review, 68, 707-729. http://dx.doi.org/10.2307/1519759

Flegal, K. M., Carroll, M. D., Kuczmarski, R. J., \& Johnson, C. T. (1998). Overweight and Obesity in the United States: Prevalence and Trends, 1960-1994. International Journal of Obesity, 22, 39-47. http://dx.doi.org/10.1038/sj.ijo.0800541

Gordon-Larsen, P., Adair, L. S., \& Popkin, B. M. (2003). The Relationship of Ethnicity, Socioeconomic Factors, and Overweight in US Adolescents. Obesity Research, 11, 121-129. http://dx.doi.org/10.1038/oby.2003.20

Gordon-Larsen, P., Adair, L. S., Nelson, M. C., \& Popkin, B. M. (2004). Five-Year Obesity Incidence in the Transition Period between Adolescence and Adulthood: The national Longitudinal Study of adolescent Health. American Journal of clinical Nutrition, 80, 569-575.

Guo, S. S., Huang, C., Maynard, L. M., Demerath, E., Towne, B., \& Chumlea, W. C. (2000). Body Mass Index during Childhood, Adolescence and Young Adulthood in Relation to Adult Overweight and Adiposity: The Fels Longitudinal Study. International Journal of Obesity and Related Metabolic Disorder, 24, 1628-1635.

Hatch, S. (2005). Conceptualizing and Identifying Cumulative Adversity and Protective Resources: Implications for Understanding Health Inequalities. Journal of Gerontology: Social Sciences, 60B, S130-S134.

Hedley, A. A., Ogden, C. L., Johnson, C. L., Carroll, M. D., Curtin, L. R., \& Flegal, K. M. (2004). Prevalence of Overweight and Obesity among US Children, Adolescents, and Adults, 1999-2002. Journal of the American Medical Association, 291, 2847-2850.

House, J. S., Kessler, R. C., Herzog, A. R., Mero, R. P., Kinney, A. M., \& Breslow, M. J. (1990). Age, Socioeconomic Status, and Health. The Milbank Quarterly, 68, 383-411. http://dx.doi.org/10.2307/3350111

House, J. S., LepKowski, J. M., Kinney, A. M., Mero, R. P., Kessler, R. C., \& Herzog, A. R. (1994). The Social Stratification of Aging and Health. Journal of Health and Social Behavior, 35, 213-234. http://dx.doi.org/10.2307/2137277

Kaplan, D. (2000). Promoting Weight Loss in the Obese Patient. Patient Care, 34, 204-218.

Kaufman, J. S., Cooper, R. S., \& McGee, D. L. (1997). Socioeconomic Status and Health in Blacks and Whites: The Problem of Residual Confounding and the Resiliency of Race. Epidemiology, 8, 621-628.

Kimm, S. Y., Barton, B. A., Obarzanek, E., McMahon, R. P., Sabry, Z., Waclawiw, M. A., et al. (2001). Racial Divergence in Adiposity during Adolescence: The NHLBI Growth and Health Study. Pediatrics, 107, E34.

http://dx.doi.org/10.1542/peds.107.3.e34

Kopelman, P. (2000). Obesity as a Medical Problem. Nature, 404, 635-643.

Kumanyika, S. (1993). Special Issues Regarding Obesity in Minority Populations. Annals of Internal Medicine, 119, 650654. http://dx.doi.org/10.7326/0003-4819-119-7_Part_2-199310011-00005

Must, A., Spadano, J., Coakley, E. H., Field, A. E., Colditz, G., \& Dietz, W. H. (1999). The Disease Burden Associated with Overweight and Obesity. Journal of the American Medical Association, 282, 1523-1529. http://dx.doi.org/10.1001/jama.282.16.1523

O’Rand, A. M. (1996). The Precious and the Precocious: Understanding Cumulative Disadvantage and Cumulative Advantage over the Life Course. The Gerontologist, 36, 230-238. http://dx.doi.org/10.1093/geront/36.2.230

Ogden, C. L., Carroll, M. D., Curtin, L. R., McDowell, M. A., Tabak, C. J., \& Flegal, K. M. (2006). Prevalence of Overweight and Obesity in the United States, 1999-2004. Journal of the American Medical Association, 295, 1549-1555. http://dx.doi.org/10.1001/jama.295.13.1549

Ogden, C. L., Flegal, K. M., Carroll, M. D., \& Johnson, C. L. (2002). Prevalence and Trends in Overweight among US Children and Adolescents, 1999-2000. Journal of the American Medical Association, 288, 1728-1732.

Pampel, F. C., \& Rogers, R. G. (2004). Socioeconomic Status, Smoking, and Health: A Test of Competing Theories of Cumulative Advantage. Journal of Health and Social Behavior, 45, 306-321. http://dx.doi.org/10.1177/002214650404500305

Patterson, M. L., Stern, S., Crawford, P. B., Mcmahon, R. P., Similo, S. L., \& Schreiber, G. B. (1997). Sociodemographic Factors and Obesity in Preadolescent Black and White Girls: NHLBI's Growth and Health Study. Journal of the National Medical Association, 89, 594-600.

Prentice, A. M., \& Jebb, S. A. (2001). Beyond Body Mass Index. Obesity Reviews, 2, 141-147. http://dx.doi.org/10.1046/j.1467-789x.2001.00031.x

Read, J. G., \& Gorman, B. K. (2006). Gender Inequalities in US Adult Health: The Interplay of Race and Ethnicity. Social Science \& Medicine, 62, 1045-1065. 
Riley, M. W. (1987). On the Signifance of Age in Sociology. American Sociological Review, 52, 1-14. http://dx.doi.org/10.2307/2095388

Ross. C. E., \& Wu, C. L. (1996). Education, Age, and the Cumulative Advantage in Health. Journal of Health and Social Behavior, 37, 104-120. http://dx.doi.org/10.2307/2137234

Schafer, M. H., \& Ferraro, K. F. (2007). Obesity and Hospitalization over the Adult Life Course: Does Duration of Exposure Increase Use? Journal of health and Social Behavior, 48, 434-449. http://dx.doi.org/10.1177/002214650704800407

Shuey, K. M., \& Wilson, A. E. (2008). Cumulative Disadvantage and Black-White Disparities in Life-Course Health Trajectories. Research on Aging, 30, 200-225. http://dx.doi.org/10.1177/0164027507311151

Sundquist, J., \& Johansson, S. E. (1998). The Influence of Socioeconomic Status, Ethnicity, and Lifestyle on Body Mass Index in a Longitudinal Study. International Journal of Epidemiology, 27, 57-63. http://dx.doi.org/10.1093/ije/27.1.57

US Department of Health and Human Services (USDHHS) (2001). The Surgeon General's Call to Action to Prevent and Decrease Overweight and Obesity. Rockville, MD: Office of the Surgeon General.

Wang, Y., \& Beydoun, M. A. (2007). The Obesity Epidemic in the United States-Gender, Age, Socioeconomic, Racial/Ethnic, and Geographic Characteristics: A Systematic Review and Meta-Regression Analysis. Epidemiologic Reviews, 1-23.

Williams, D. (1997). Race and Health: Basic Questions, Emerging Directions. Annals of Epidemiology, 7, 322-333. http://dx.doi.org/10.1016/S1047-2797(97)00051-3

Williams, D. (2008). The Health of Men: Structured Inequalities and Opportunities. American Journal of Public Health, 98, S150-S157.

Zhang, O., \& Wang, Y. (2004). Trends in the Association between Obesity and Socioeconomic Status in U.S. Adults: 1971 to 2000. Obesity Research, 12, 1622-1632. http://dx.doi.org/10.1038/oby.2004.202 
Scientific Research Publishing (SCIRP) is one of the largest Open Access journal publishers. It is currently publishing more than 200 open access, online, peer-reviewed journals covering a wide range of academic disciplines. SCIRP serves the worldwide academic communities and contributes to the progress and application of science with its publication.

Other selected journals from SCIRP are listed as below. Submit your manuscript to us via either submit@scirp.org or Online Submission Portal.
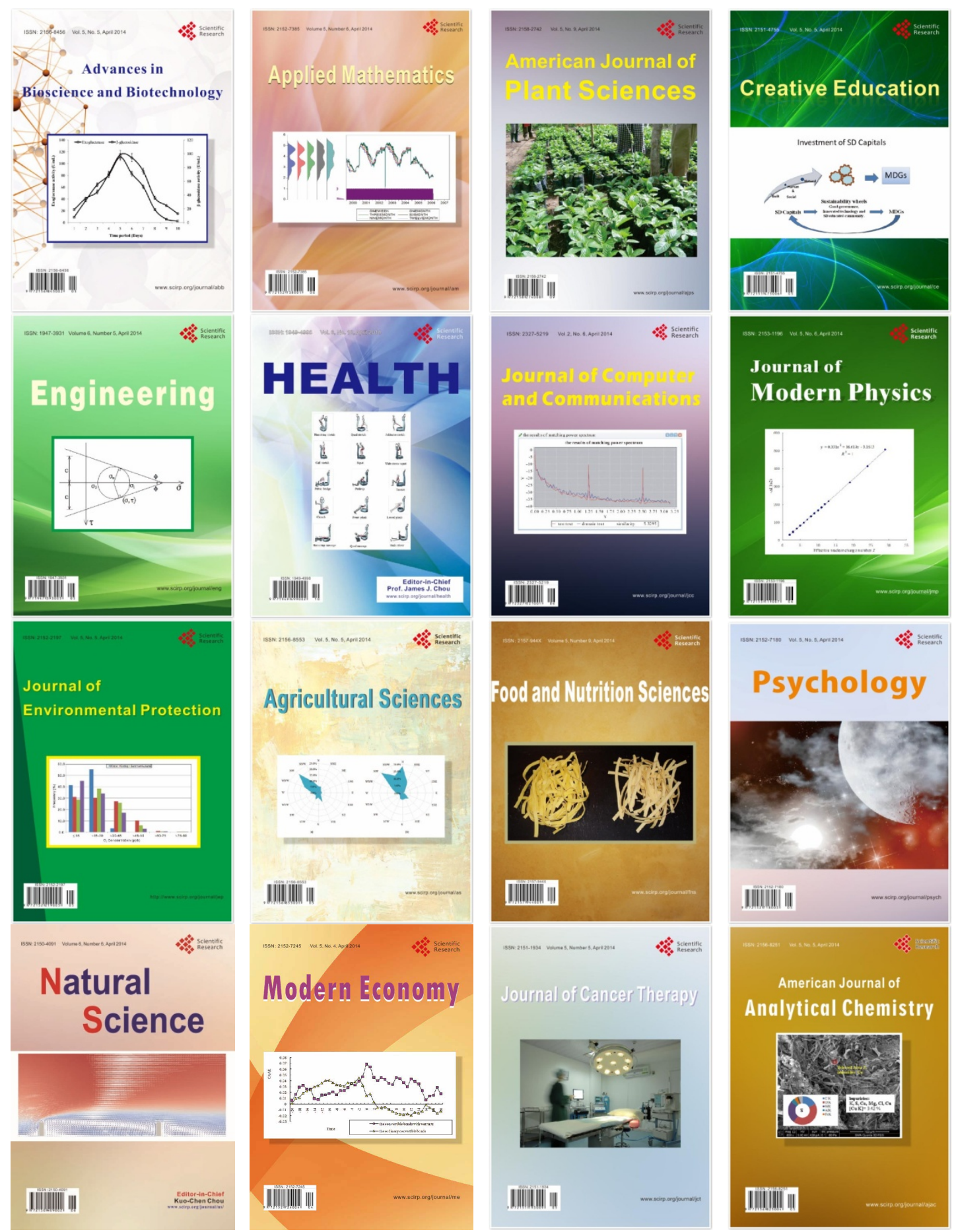